\title{
Investigating the international prices of wheat and rice
}

\author{
Anthony N Rezitis ${ }^{1,2^{*}}$, Anastasia G Ntinou ${ }^{2}$ and Dimitris N Pachis ${ }^{2}$
}

\author{
* Correspondence: \\ antonios.rezitis@helsinki.fi \\ ${ }^{1}$ Economics and Management, \\ University of Helsinki, \\ Latokartanokaari 9, P.O.Box 27, \\ Helsinki, Finland \\ ${ }^{2}$ Business Administration of Food \\ and Agricultural Enterprises, \\ University of Patras, G. Seferi 2, \\ Agrinio 30100, Greece
}

\begin{abstract}
This paper investigates the international quarterly prices of wheat and rice from 1983(1) to 2012(4). The empirical analysis takes place with the structural time series methodology which decomposes the price series into their trend, cycle, seasonal and irregular components. The empirical results indicate that wheat prices present cyclical behavior while rice prices except for cyclicality are mainly governed by the irregular component. The results strain the importance of treating wheat and rice like two distinct commodities that require country specific and commodity specific policy measures. Finally, the impact of the shrinking Chinese grain stocks after 2002 is proposed as an important factor that resulted in the 2008 price spike.
\end{abstract}

Keywords: Structural time series; International prices; Wheat; Rice

\section{Background}

From late 2006 through to mid-2008, the world witnessed unusual price increases in major agricultural commodities like wheat and rice (Dethier and Effenberger, 2011). However, until then, the world was used to generally low price variability in agricultural commodities especially after the volatile decades of 1970s and 1980s (Gilbert, 2006). This episode renewed the interest in agricultural commodities since they are tightly connected to food security, particularly in developing and underdeveloped countries. Moreover, developed countries were also concerned because price spikes adversely affect the welfare of producers and consumers. Therefore, the analysis of international agricultural commodity prices has once again been under the spotlight in agricultural economics research. This research has mainly focused on investigating the reasons for the price spike between 2006 and 2008. However, it has also enriched the literature with new insights into the drivers of agricultural commodities price changes. The price formation of agricultural commodities is mainly attributed to the variation of the market fundamentals, which are the supply and demand. Following Gilbert and Morgan (2010), natural shocks caused by weather conditions or diseases and the area planted are the main factors that affect production. Moreover, technological infrastructure is a key driver of the quantity produced. On the other hand, consumption varies because of changes in income levels or, in the prices of substitutes, or because of shifts in tastes. The extent to which given production and consumption shocks translate into the formation of prices depends on supply and demand elasticities, which reflect the responsiveness of producers and consumers to price changes. The supply and demand

(c) 2015 Rezitis et al. This is an Open Access article distributed under the terms of the Creative Commons Attribution License (http:// creativecommons.org/licenses/by/4.0), which permits unrestricted use, distribution, and reproduction in any medium, provided the original work is properly credited. 
price elasticities are low in the short run (during the cropping period), especially if the stocks of agricultural products are low (Wright and Williams, 1991; Deaton and Laroque, 1992). Apart from market fundamentals, sudden shifts in policy (Christiaensen, 2009), input prices, exchange rates, and trading patterns as well as speculation, affect price formation (Interagency Report, 2011; Gilbert and Morgan, 2010). Furthermore, the ever strengthening relationship between agricultural commodities and energy prices (oil and biofuels) will continue to bind them together, while the effect of macroeconomic fundamentals should not be overlooked (OECD, 2008).

The purpose of this paper is to investigate the formation of the international prices of wheat and rice. Wheat is a staple that is produced and consumed mainly in temperate regions, while it is also used as an input into the production of meat products. The main producers and exporters of wheat are the United States, the European Union, Canada, Australia, Argentina, and more recently the Russian Federation, Ukraine, and Kazakhstan (FAO, 2009). Wheat is a commodity that is freely traded internationally. On the other hand, rice is a staple in Southeast Asian countries, in central and West Africa, in the Caribbean as well as in South America. Southeast Asian countries account for approximately 25 percent of global production (Baldwin et al., 2012). Furthermore, a small amount of rice is traded internationally; its price is not freely determined by the market but it is sold or bought in contracted prices (Timmer, 2010). The aforementioned characteristics of wheat and rice indicate that they are not correlated in terms of production, consumption, or trade patterns. Wheat is a staple in richer countries where meat consumption is also high, whereas rice is a staple in poorer countries. Thus, their price shocks are not interdependent, especially since rice is traded in the futures markets of Chicago and Bangkok at low volumes. The increased prices of these two staples have affected several countries, which in their efforts to protect their domestic markets have applied export restrictions and tariffs. However, these actions have reduced the amount of traded grains internationally, which is something that has exacerbated the price increases (Abbott et al., 2011). After the 2006-2008 crisis, the price levels decreased, but without going back to their previous levels.

A researcher has the option of using different classes of models for the modeling of the observed as well as the unobserved price changes of a time series. A popular choice for the modelling of prices is the AutoRegressive Integrated Moving Average (ARIMA) model. This class of models was advocated by Box and Jenkins (1976) and its key attribute is the pursuit of stationarity with as much differencing as necessary. The problem with differencing is to know when it has eliminated enough of the trending and the seasonality of a time series, whilst the identification of the model by the sample autocorrelation function is imprecise due to its high sampling variability. However, ARIMA models are good for forecasting since the elimination of the trend and the seasonal component is not a problem (Durbin and Koopman, 2012). Another popular choice for the modeling of the relationships between prices is the Vector AutoRegressive model of Sims (1982). Nowadays, this class of models is based on the search for unit roots that indicate the presence of trending or seasonal behavior, and eliminate them by differencing as well as by the addition of a co-integrated relationship among the variables representing their common trend. The study of unobserved price changes in a series takes place by the use of (Generalized) AutoRegressive Conditional Heteroskedastic ([G]ARCH) models proposed by Bollerslev (1986) and Engle (1982), respectively. This 
class of models was frequently used by researchers for the study of the price spike in agricultural commodities from late 2006 to mid-2008. These three classes of models attempt to model the price series formation and interactions by abandoning the structure of a fully specified model. A fully specified model attempts to use as many explanatory variables as possible for the modeling of a price series. However, no matter how many explanatory variables one could use, the researcher will be partly able to account for the variability of the time series. Thus, the fourth class of model, the Structural Time Series (STS) model, maintains the structure of the time series, which is composed of trend and, seasonal, cyclical, and irregular components, without however attempting to build a fully specified model. The trend determines the direction shifts occurring with permanent changes representing the long-term nature of the series. Seasonal effects are related to natural conditions. The cycle represents the magnitude and the length of fluctuations that occur in the short run, while the irregular component identifies unexpected events. Kalman (1960) introduced the STS models with the aim of addressing a wide variety of problems by means of their flexibility. A key aspect of the STS models is that the pursuit of stationarity is not necessary since the time series components such as trend and, seasonal and cyclical factors can accommodate evolving distributions over time. Moreover, an STS model does not aim to represent the underlying data generating process, but it represents the stylized facts of the price series in terms of the decomposition. Therefore, the structural nature of the model allows for direct interpretation (Harvey, 1989).

Structural time series analysis has been used for the investigation of many price series that are quite different in their nature. This paper next points out a number of relevant studies that have analyzed the price series relevant to agricultural markets. In particular, Ubide (1997) investigated inflation in Mozambique and showed that the seasonal behavior of inflation is affected by agricultural products' seasonality. Faliva (1994) analyzed Italian unemployment in the agricultural sector. Shepherd (2006) used a structural time series model for the world cotton supply. Furthermore, Fatiga and Misra (2007) used a multivariate unobserved components model for cotton, wool, rayon, and polyester world prices. In their study, Crispin and Dale (1998) studied the US broiler industry and found that a significant role is played by the feed costs as well as technology advances. A similar study carried out by Chidmi and Fatiga (2007) examined the formation of US beef, pork, and poultry prices using a multivariate unobserved components approach. Farley and Murphy (1997) studied sockeye salmon stocks in Alaska and northern British Columbia with the intention of explaining the trending behavior of the sockeye salmon catch. Bhar and Hamori (2007) investigated corn, soybean and sugar futures' prices in order to extract information about the short and long-term dynamics of each series. Moreover, Heymans (2008) employed the unobserved component model in white and yellow maize futures prices. In a recent paper, Rezitis and Sassi (2013) analyzed the price movements of a commodity price index and provided future price predictions. Mirzabaev and Tsegai (2012) examined the impact of adverse weather conditions in Central Asia on wheat and potato price series and found that unfavorable weather conditions lead to higher wheat and potato prices, while the international price spikes of primary commodities negatively affect domestic prices.

In this study, the international prices of wheat and rice are investigated with a univariate Structural Time Series model. The analysis decomposes the price series to their unobserved components of trend and, seasonal, cyclical, and irregular without searching 
for any commonalities, since the market characteristics of the two products set them apart. Furthermore, the information acquired for the past behavior of the series are then used for forecasting. This study enriches the literature on the international price formation of agricultural commodities by utilizing a method that is not based on the properties of the time series but on the stylized facts that govern the series. Therefore, better forecasts can be achieved, whilst the interpretation of the results is straightforward due to the structural form of the model used. Moreover, the structural breaks and the temporal effects of the series can be identified and modeled leading to a model with a better fit to the data. The empirical analysis shows that wheat prices present cyclical behavior while rice prices, except for cyclicality, are governed by the irregular component. The results identify the role of the decreased Chinese stocks in the path of events that led to the 2008 price spike while underlining the importance of commodity and country-specific policy measures for wheat and rice.

The paper proceeds as follows: in section 2 the theoretical framework of the model is presented; section 3 focuses on data presentation; the empirical results are provided in section 4; and, discussion and conclusions are presented in sections 5 and 6, respectively.

\section{Methods}

The structural time series methodology by Koopman et al. (2009) is used to decompose the wheat and rice price series into trend, seasonal, cycle and irregular components. Letting the logarithm of wheat or rice prices presented by $y_{t}$ then the stochastic linear model is given by:

$$
y_{t}=\mu_{t}+\gamma_{t}+\psi_{t}+\sum_{j=1}^{h} \lambda_{j} d_{j, t}+\varepsilon_{t}, \varepsilon_{t} \sim \mathrm{N}\left(0, \sigma_{\varepsilon}^{2}\right)
$$

where $\mu_{t}$ is the trend, $\gamma_{t}$ is the seasonal, $\Psi_{t}$ is the cycle, $d_{j, t}$ is an intervention (dummy) variable and $\varepsilon_{t}$ is the irregular component.

In the present analysis the modelling procedure showed that the trend and seasonal components are fixed. Specifically, the trend component is defined as:

$$
\mu_{t}=\mu_{t-1}+\beta_{t-1}+\eta_{t}, \text { where } \eta_{t} \sim \mathrm{N} I D\left(0, \sigma_{\eta}^{2}\right), \sigma_{\eta}^{2}=0
$$

where $\beta_{t}$ is the slope of the trend which is defined as :

$$
\beta_{t}=\beta_{t-1}+\zeta_{t} \text { where } \zeta_{t} \sim N I D\left(0, \sigma_{\zeta}^{2}\right), \sigma_{\zeta}^{2}=0
$$

The irregular $\varepsilon_{t}$, the level disturbance $\left(\eta_{t}\right)$ and the slope disturbance $\left(\zeta_{t}\right)$ are mutually interrelated, where $\eta_{t}$ and $\zeta_{t}$ are normally and independently distributed white noise processes with zero means and variance $\sigma_{\eta}^{2}$ and $\sigma_{\zeta}^{2}$ respectively. Moreover, seasonality is the systematic calendar related influence that is captured by the seasonal component $\gamma_{t}$. The seasonal component has a trigonometric deterministic seasonal structure, which is given by: 


$$
\gamma_{t}=\sum_{i=1}^{[s / 2]} \gamma_{j, t}
$$

where each $\gamma_{j, t}$ is generated by :

$$
\left[\begin{array}{l}
\gamma_{j, t} \\
\gamma_{j t}^{*}
\end{array}\right]=\left[\begin{array}{c}
\cos \lambda_{j} \sin \lambda_{j} \\
-\sin \lambda_{j} \cos \lambda_{j}
\end{array}\right]\left[\begin{array}{c}
\gamma_{j, t-1} \\
\gamma_{j, t-1}^{*}
\end{array}\right]+\left[\begin{array}{c}
\omega_{j, t} \\
\omega_{j, t}^{*}
\end{array}\right], j=1, \ldots .,[s / 2], \quad t=1, \ldots, T
$$

Note that the $\lambda_{j}=2 \pi / \mathrm{s}$ is the frequency, in radians, while the seasonal disturbances $\omega_{t}$ and $\omega_{t}^{*}$ are two mutually uncorrelated normally and independently distributed disturbances with zero mean and common variance $\sigma_{\omega}^{2}$. Since, the seasonal component has a deterministic form then $\sigma_{\omega}^{2}=0$. For $s$ even, the component at $j=\mathrm{s} / 2$ collapses to:

$$
\gamma_{j, t}=\gamma_{j, t-1} \cos \lambda_{j}+\omega_{j, t}
$$

The statistical specification of a cycle $\psi_{t}$ is given by:

$$
\left[\begin{array}{l}
\psi_{t} \\
\psi_{t}^{*}
\end{array}\right]=\rho_{\psi}\left[\begin{array}{c}
\cos \lambda_{c} \sin \lambda_{c} \\
-\sin \lambda_{c} \cos \lambda_{c}
\end{array}\right]\left[\begin{array}{l}
\psi_{t-1} \\
\psi_{t-1}^{*}
\end{array}\right]+\left[\begin{array}{c}
\kappa_{t} \\
\kappa_{t}^{*}
\end{array}\right], t=1, \ldots ., T
$$

where $\rho_{\psi}$ is the damping factor $\left(0<\rho_{\psi} \leq 1\right)$ which reflects the speed with which various price fluctuations are dampened, $\lambda_{c}$ is the frequency $\left(0<\lambda_{c} \leq \pi\right)$ in radians that defines the magnitude of the fluctuations of the price series and $K_{t}, \kappa_{t}^{*}$ are two mutually uncorrelated normally and independently distributed disturbances with zero mean and common variance $\sigma_{\kappa}^{2}$. The duration of the cycle is $2 \pi / \lambda_{c}$, showing the time length to complete the fluctuations. Higher order cycles are used for smoothing the extracted cycles. An $n$ th-order univariate cycle is defined by

$$
\begin{aligned}
& {\left[\begin{array}{l}
\psi_{1, t} \\
\psi_{1, t}^{*}
\end{array}\right]=\rho\left[\begin{array}{c}
\cos \lambda_{c} \sin \lambda_{c} \\
-\sin \lambda_{c} \cos \lambda_{c}
\end{array}\right]\left[\begin{array}{l}
\psi_{1, t-1} \\
\psi_{1, t-1}^{*}
\end{array}\right]+\left[\begin{array}{l}
\kappa_{t} \\
\kappa_{t}^{*}
\end{array}\right]} \\
& {\left[\begin{array}{l}
\psi_{i, t-1} \\
\psi_{i, t-1}^{*}
\end{array}\right]=\rho\left[\begin{array}{c}
\cos \lambda_{c} \sin \lambda_{c} \\
-\sin \lambda_{c} \cos \lambda_{c}
\end{array}\right]\left[\begin{array}{l}
\psi_{i, t-1} \\
\psi_{i, t-1}^{*}
\end{array}\right]+\left[\begin{array}{l}
\psi_{i-1, t-1} \\
\psi_{i-1, t-1}^{*}
\end{array}\right], i=2, \ldots ., n} \\
& {\left[\begin{array}{c}
\kappa_{t} \\
\kappa_{t}^{*}
\end{array}\right] \sim N I D\left(\left[\begin{array}{l}
0 \\
0
\end{array}\right],\left[\begin{array}{cc}
\sigma_{\kappa}^{2} & 0 \\
0 & \sigma_{\kappa}^{2}
\end{array}\right]\right)}
\end{aligned}
$$

where $\kappa_{t} \sim N I D\left(0, \sigma_{\kappa}^{2}\right)$. The parameter $\rho$ is called the damping factor $(0<\rho \leq 1)$ while 0 $<\lambda_{c} \leq \pi$. Finally, intervention variables $d_{j, t}$ are dummy (indicator) variables that are used to capture structural breaks or outlying (irregular) observations. The structural break is related to the unusual value of the level disturbance of the series and is modeled by a step intervention variable which is zero before the event and one after. An outlier can be captured by an impulse intervention that takes the value of one at the time of the outlier and zero elsewhere. Structural breaks represent unusual permanent changes while outliers represent unusual temporary changes. Moreover, a large value of the slope disturbance can be thought as a structural break in the slope and is modeled as a staircase intervention where the trend variable takes the values $1,2,3, \ldots$ starting in the period after the break. The introduction of structural breaks and outliers in unobserved component models enhance the estimation of parameters and provide effective forecasts. 
The data-set ${ }^{1,2}$ used consists of quarterly data of the logarithm of the prices of wheat (Lhard-Wh) referring to Hard Red Winter and rice (LRice) referring to Thailand rice from 1983(1) to 2012(4). The aforementioned data are obtained from the World Bank, are measured in US Dollars per Metric Ton and are nominal. Figs. 1 and 2 show the evolution of the logarithm of wheat (Lhard-Wh) and rice prices (LRice). The graphs indicate that up to 2002 both rice and wheat prices exhibit cyclical behavior with a slight increasing trend while a seasonal pattern is observed. However, after 2002 the cyclical behavior is disrupted and the uprising trend becomes much steeper. In 2008 this upward movements reaches its peak. After 2008 prices decreased but they persisted in higher levels than before.

The descriptive statistics of the price series in levels and logarithms are reported in Table 1.

\section{Results}

The structural time series models of wheat and rice are estimated by maximum likelihood. The price series are decomposed in their components by the smoothing algorithm proposed in Koopman et al. (2009). The most appropriate model for wheat consists of a trend with level and slope, a second order seasonal, two cycles of order one and interventions. The wheat decomposition is presented in Fig. 3. For rice, the model is comprised by a trend with level, seasonal, two cycles of order two, interventions and irregular while is exhibited in Fig. 4. The smoothing algorithm showed very strong convergence for both price series.

Table 2 presents the diagnostics and goodness-of-fit statistics of the $\log$-likelihood (LogL), the normality test following a $\chi^{2}$ distribution with 2 degrees of freedom $\left(N\left(X_{2}^{2}\right)\right)$, a heteroskedasticity test following a $\mathrm{F}$ distribution with $(33,33)$ degrees of freedom for wheat $\left(\mathrm{H}_{35}\left(\mathrm{~F}_{35,35}\right)\right)$ and $(35,35)$ degrees of freedom $\left(\mathrm{H}_{35}\left(\mathrm{~F}_{35,35}\right)\right)$ for rice. Moreover, the classical Durbin-Watson test statistic (DW), a Box-Ljung statistic based on the first 16

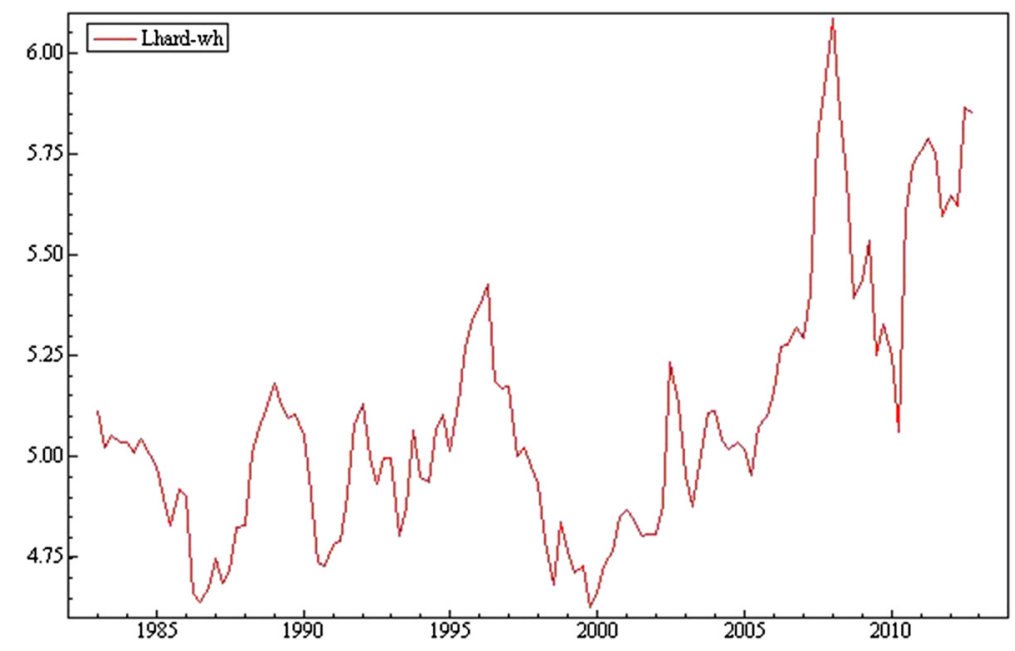

Fig. 1 Evolution of Wheat price index. (Lhard-Wh) from 1983(1) to 2012(4) 


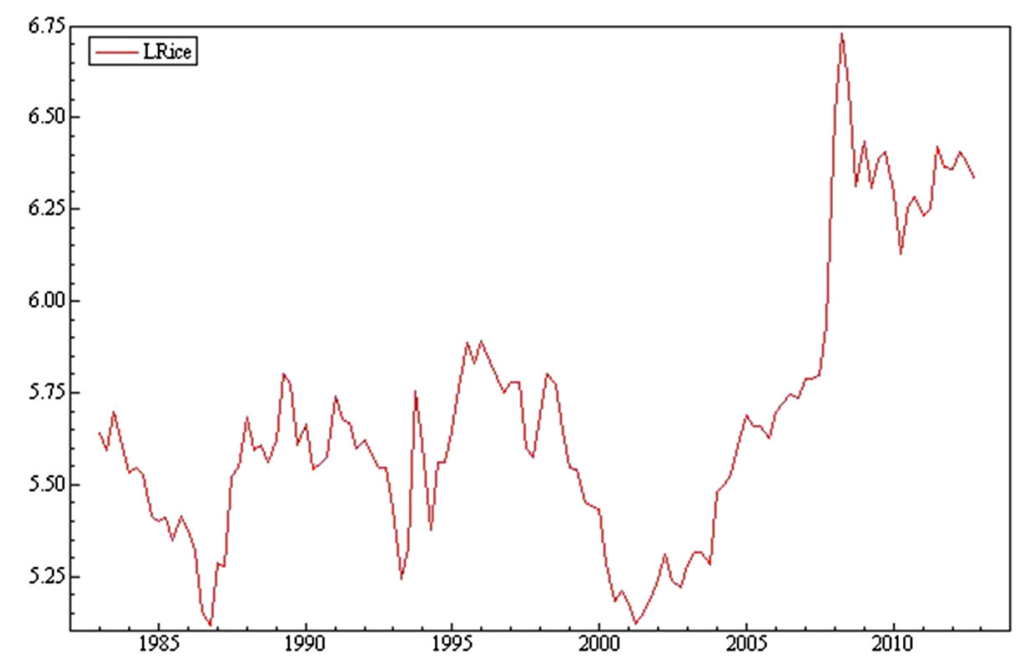

Fig. 2 Evolution of Rice price index. (LRice) from 1983(1) to 2012(4)

autocorrelations tested against a $\chi^{2}$ distribution with 9 degrees of freedom $(Q(16,9))$ and the coefficient of determination $\left(\mathrm{R}^{2}\right)$ are presented for both price series.

The residuals are assumed to be normally and independently distributed in a correctly specified model. The standardized residuals as well as their correlogram, spectral density and density are shown in Figs. 5 and 6 for wheat and rice prices, respectively.

The statistics exhibited in Table 2 and the graphs presented in Figs. 3 and 4 show that the estimated models are robust. More specifically, the correlogram and spectral density suggest that the residuals are not autocorrelated since the theoretical spectrum for white-noise residuals is a horizontal straight line. Furthermore, the aforementioned statistics do not give evidence of misspecifications in the estimated models.

Table 3 presents the q-ratios showing the variances of the disturbances of the components affecting the structure of the price series. For wheat, cycles 1 and 2 account for the majority of the fluctuations since the trend, the seasonal and the irregular components are fixed. Regarding rice prices, most of the fluctuations are attributed, apart from cycles 1 and 2, to the irregular component since trend and seasonal are fixed. Furthermore, the q-ratios indicate that the fluctuations of cycle 2 are mainly responsible for variations of wheat prices while the fluctuations of irregular are mainly responsible for variations of rice prices.

The parameters of cycle 1 and 2 for wheat and rice prices are depicted in Table 4 . More specifically, the shorter cycle for wheat (cycle 1 ) has a variance of 0.002 , a period of 1.75 years and a damping factor of 0.986 while the longer cycle (cycle 2) has a variance of 0.019 , a period of 7.7 years and a damping factor of 0.906 . The shorter cycle for rice (cycle 1) has a variance of 0.001 , a period of 1.1 years and a damping factor of 0.515 while the longer cycle (cycle 2) has a variance of 0.002 , a period of 15.5 years,

Table 1 Descriptive statistics

\begin{tabular}{lcclcc}
\hline Variables & Means & Standard Deviations & Variables (logarithms) & Means & Standard Deviations \\
\hline Wheat & 173.0 & 65.83 & Lhard-Wh & 5.096 & 0.32 \\
Rice & 314.9 & 134.9 & LRice & 5.679 & 0.36 \\
\hline
\end{tabular}

Notes: Rice stands for the rice price index $(2005=100)$, Hard Wheat stands for the Hard Wheat price index $(2005=100)$ 


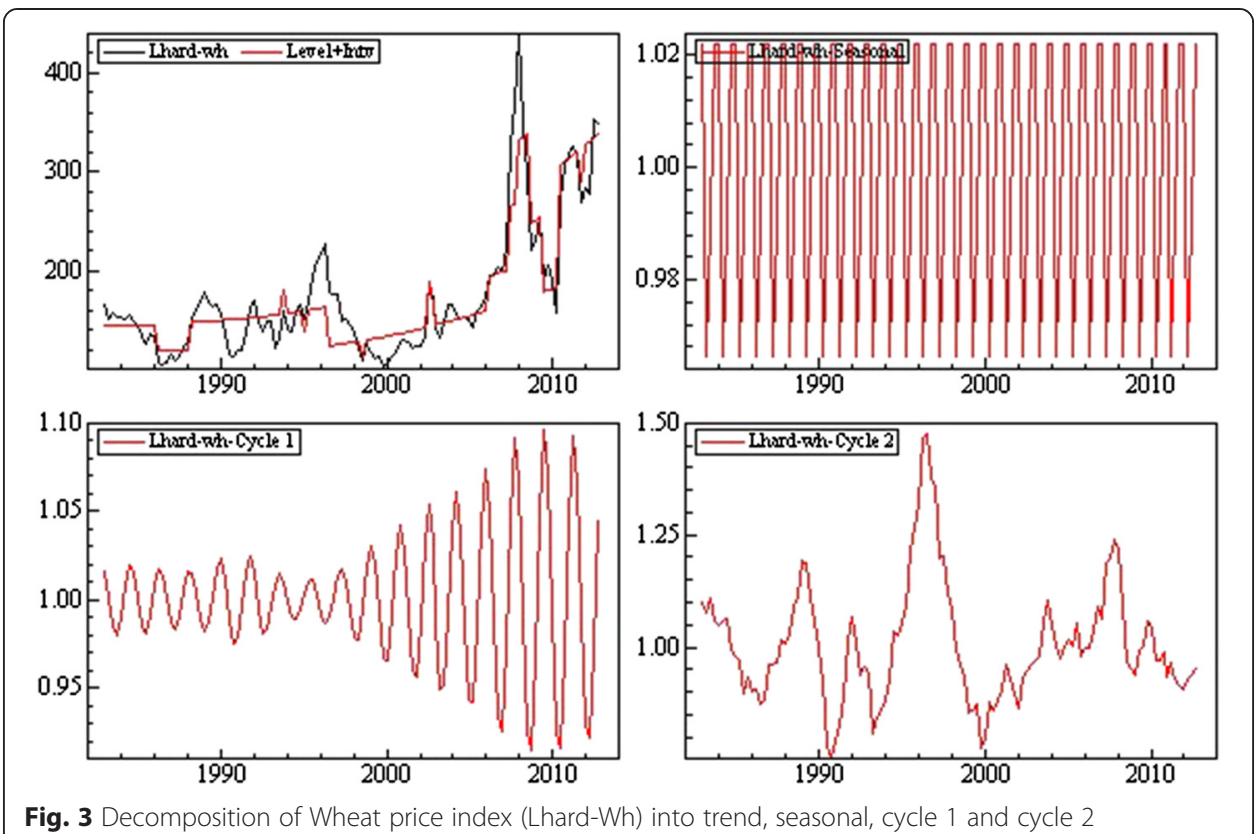

and a damping factor of 0.814 . The cycles of both wheat and rice prices show high degree of persistence as is clearly depicted in Table 4.

The maximum likelihood estimates of the final state vector and the regression effects (intervention dummies) of wheat and rice are presented in Table 5 while the state vector anti-log analysis is presented in Table 6. With respect to wheat, the level $\mu_{\mathrm{T}}$ of the price index at the end of the period (2012(4)) is 269.9 (see Table 6) which is well above the mean value of 173.0 (see Table 1). Furthermore, the slope component is significant indicating that the growth rate of wheat prices is $4.5 \%$ per year (see Table 5). The

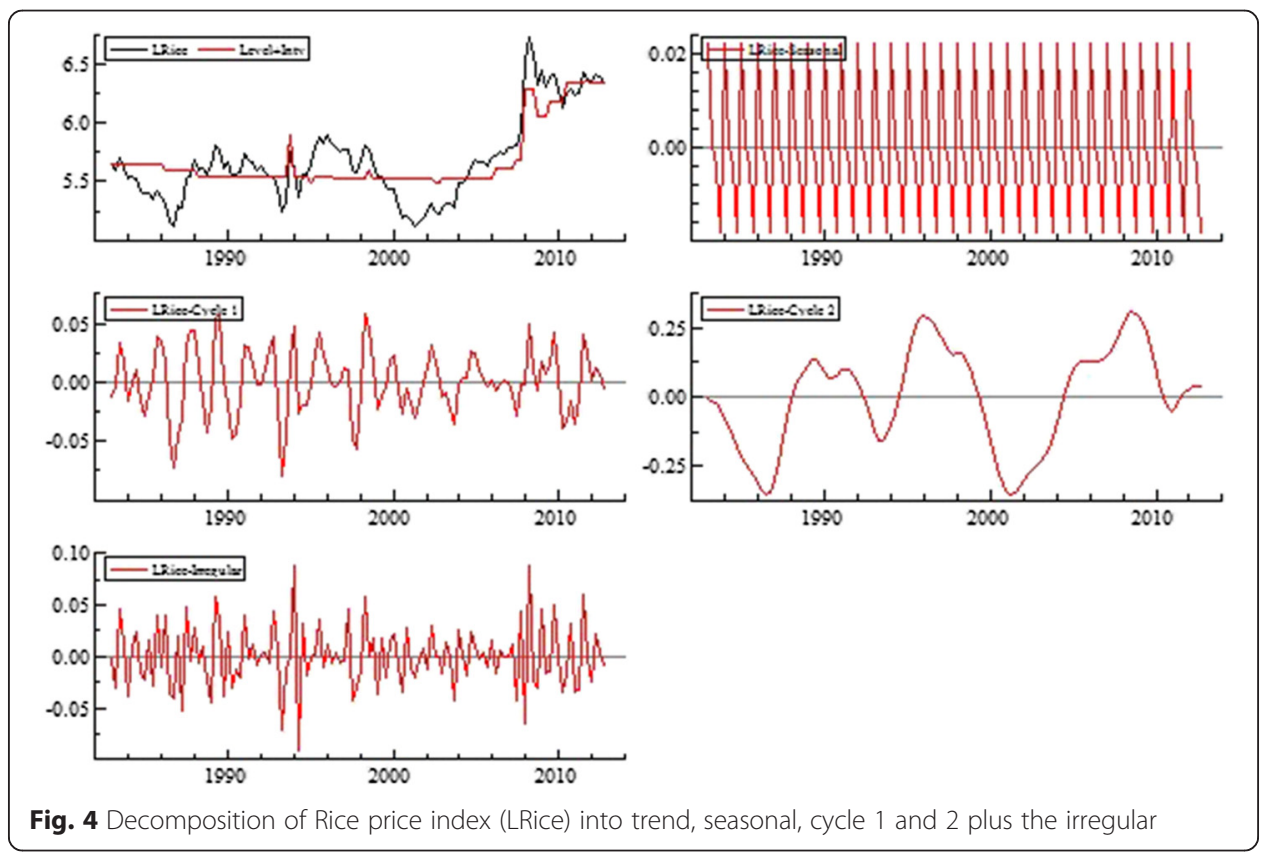


Table 2 Diagnostics and goodness-of-fit statistics for Rice and Wheat

\begin{tabular}{llllllll}
\hline Statistics & LogL & $N\left(x_{2}^{2}\right)$ & $\mathrm{H}_{35}\left(\mathrm{~F}_{35,35}\right)$ & $\mathrm{H}_{33}\left(\mathrm{~F}_{33,33}\right)$ & $\mathrm{DW}$ & $\left.\mathrm{Q}_{(15,9}\right)$ & $\mathrm{R}^{2}$ \\
\hline Wheat & 245.7 & $0.005[0.997]$ & - & $1.565[0.101]$ & 1.768 & $13.81[0.128]$ & 0.78 \\
Rice & 268.5 & $0.168[0.919]$ & $0.658[0.889]$ & - & 1.902 & $9.118[0.426]$ & 0.67 \\
\hline
\end{tabular}

Notes: Values in brackets are p-values

magnitude of cycle 1 as a percentage of the trend is $4.5 \%$ (see Tables 5 and 6). The seasonal effect as well as 3 out of 4 individual seasonal effects are statistically significant (see Tables 5 and 6). In particular, the individual seasonal effects indicate that wheat price is on average $2.2 \%$ higher in the first and fourth quarters of the year and on average 3.4 \% lower in the second quarter (see Table 6). Regarding rice, the level $\mu_{\mathrm{T}}$ of the price index at the end of the period (2012(4)) is 243.8 (see Table 6) which is well below the mean value of 314.9 (see Table 1). In addition, the amplitude of cycle 1 as a percentage of the level is $4.9 \%$ (see Tables 5 and 6). The seasonal effect is statistically significant whereas the individual seasonal effects are not (see Tables 5 and 6).

Moreover, Table 5 shows the structural breaks and the outliers that were detected in the two price series. The detection took place with an inherent procedure of the estimation process. The incorporation of these intervention variables to the two models improved the consistency and the efficiency of the estimates. The intervention effects for both cereals are statistically significant. For wheat nine of the intervention effects are related to structural breaks while six are related to outliers. Five of the structural breaks have a positive effect on price level while four have negative effect. Moreover, three of the outliers have a positive effect while the remaining three negative effect. In particular, the upward shift in the trend of wheat prices is depicted by the 1988(2), 2006(2), 2007(3), 2008(1) and 2010(3) structural breaks while the downward shift in the trend by the 1986(2), 1996(3), 2008(4) and 2009(3) structural breaks. Additionally, the outliers indicating a positive shift are 1993(4), 2002(3) and 2002(4) while the outliers indicating a negative shift are 1995(1), 1998(3) and 2011(4). The intervention effects for rice are eight structural breaks and two outliers. Half of the structural breaks have a positive effect on the price level while the rest have negative. Both outliers have a
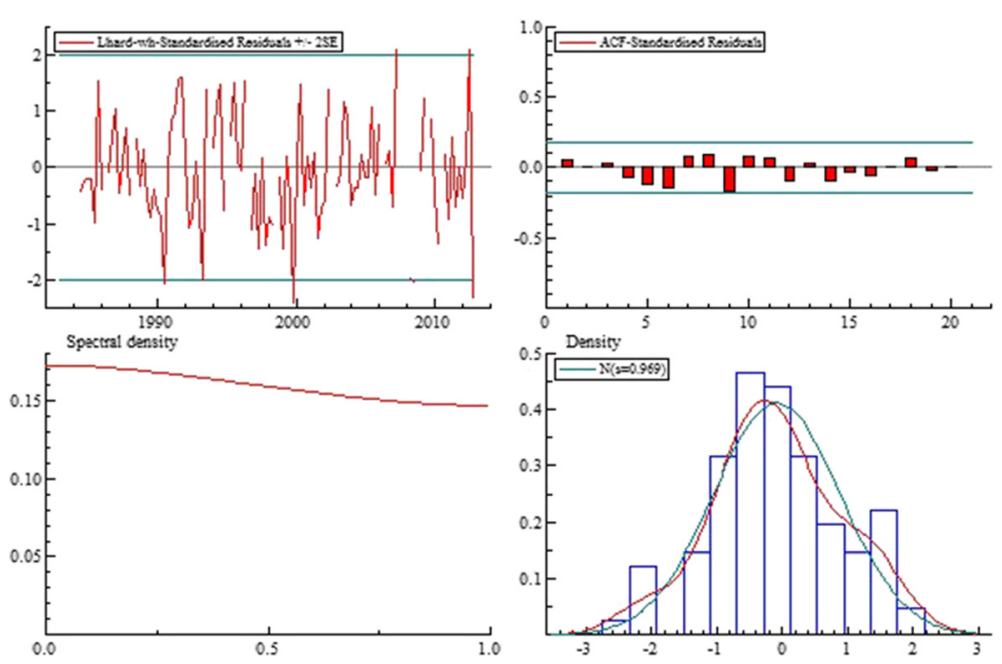

Fig. 5 Wheat prices (Lhard-Wh) residuals 

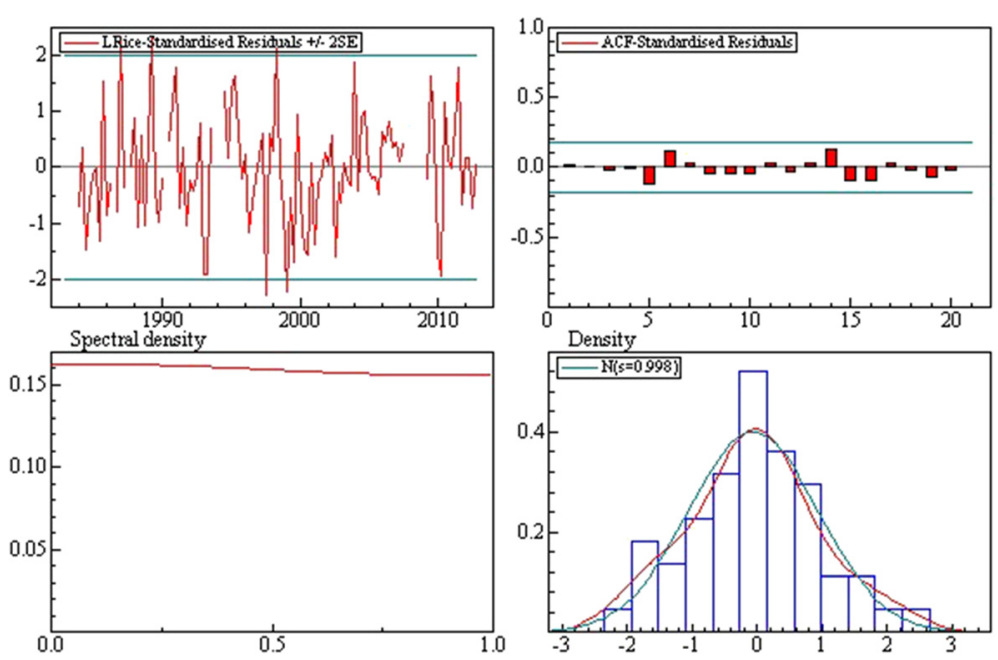

Fig. 6 Rice prices (LRice) residuals

positive effect. The structural breaks associated with an upward shift are 1987(3), 1993(4), 2007(4) and 2008(2) while a downward shift is indicated by 1986(3), 1990 (2), 1994(2) and 2008(4) interventions. Furthermore, the two positive outliers are 2008(1) and 2009(1). Next, the diagnostic tests on the auxiliary residuals for wheat and rice price indices are depicted in Table 7 . The tests verify that are normally distributed.

The auxiliary residuals graphs of wheat and rice prices are shown in Figs. 7 and 8. It is evident from the graphs that the t-values, corresponding to the estimated auxiliary residuals, do not exceed three in absolute value, indicating that the most extreme interventions have been included in the model.

The predictions for wheat (Lhard-Wh) and rice (LRice) price indices are displayed in Figs. 9 and 10, respectively. The out of sample forecast for wheat is from 2012(1) to 2012(4) while for rice is from 2011(1) to 2012(4). The predicted prices and their residuals are within the prediction intervals of two root mean square errors (RMSEs). The stability and accuracy of the forecasts is confirmed by the CUSUM graphs presented in Figs. 9 and 10 for wheat and rice, respectively. Thus, the estimated models for wheat and rice are proved appropriate.

Finally, Table 8 presents the post-sample predictive tests that validate the aforementioned argument.

Table 3 Variance of disturbances: values and q-ratio

\begin{tabular}{lll}
\hline Variance disturbances & Wheat: values [q-ratio] & Rice: values [q-ratio] \\
\hline$\sigma_{\eta}^{2}$ (level) & $0.000[0.000]$ & $0.000[0.000]$ \\
$\sigma_{\zeta}^{2}$ (slope) & $0.000[0.000]$ & - \\
$\sigma_{\omega}^{2}$ (seasonal) & $0.000[0.000]$ & $0.000[0.000]$ \\
$\sigma_{\kappa_{1}}^{2}$ (cycle 1) & $0.000[0.016]$ & $0.000[599.2]$ \\
$\sigma_{K_{2}}^{2}$ (cycle 2) & $0.003[1.000]$ & $0.000[632.3]$ \\
$\sigma_{\varepsilon}^{2}$ (irregular) & $0.000[0.000]$ & $0.000[1.000]$ \\
\hline
\end{tabular}

Notes: q-ratio in brackets is the ratio of each variance to the largest 
Table 4 Parameters of cycles 1 and 2

\begin{tabular}{|c|c|c|}
\hline Parameters & Wheat: values & Rice: values \\
\hline & \multicolumn{2}{|c|}{ Cycle 1} \\
\hline$\sigma_{\psi_{1}}^{2}$ (variance) & 0.002 & 0.001 \\
\hline $2 \pi / \lambda_{c 1}$ (duration) & (1.75 yrs) & (1.1 yrs) \\
\hline$\lambda_{c 1}$ (frequency) & 0.904 & 1.05 \\
\hline \multirow[t]{2}{*}{$\rho_{\psi_{1}}$ (damping factor) } & 0.986 & 0.515 \\
\hline & \multicolumn{2}{|c|}{ Cycle 2} \\
\hline$\sigma_{\psi_{2}}^{2}$ (variance) & 0.019 & 0.002 \\
\hline $2 \pi / \lambda_{c 2}$ (duration) & (7.7 yrs) & (15.5 yrs) \\
\hline$\lambda_{c 2}$ (frequency) & 0.21 & 0.11 \\
\hline$\rho_{\psi_{2}}$ (damping factor) & 0.906 & 0.814 \\
\hline
\end{tabular}

\section{Discussion}

During the period under investigation from 1983 (quarter 1) to 2012 (quarter 4), wheat and rice markets encountered many shocks of a permanent (structural breaks) as well as transitory (outliers) nature. First of all, there were shocks in the market fundamentals of supply and demand. While improved farming technologies have positively affected production, the continuing de-investment in the agricultural sector has resulted in reduced utilization of the capacity of the agricultural economic resources. The continuously increasing population and the development of the biofuels market have put pressure on the demand side. These forces have affected the creation and conservation of stocks, leading to cyclicality effects in the prices, even when supply and demand shocks were independent over time. Up to 2002 the grain stocks were kept at satisfactory levels, mainly due to the increased production of China; however, after this point, China reduced its stocks, thus affecting the worldwide stock reserves significantly (Baffes and Haniotis, 2010). Moreover, the regulatory framework for grain has changed globally after the negotiations of the World Trade Organization. The big producer countries, especially the United States and the European Union, were under pressure to open up their markets. Furthermore, during this long period unfavorable weather conditions affected production more than once. Speculation, exchange rates, and energy prices have also played their part in the formation of the prices. The interaction of these factors resulted in a pattern of prices for both of these commodities that followed a relatively steady trend with cyclical and seasonal effects. However, after 2002, the price of wheat started to exhibit increasing price fluctuations that reached their peak in 2008. Rice reached a price spike in 2008 as well, despite the fact that there was no change in the market fundamentals. Current literature proposes different explanations for this episode. However, there is a converging agreement that this spike was not just the result of market-specific factors. There is a consensus that a generally increasing trend in quite a few major economic variables has led to increased prices beyond the influence of market fundamentals. However, the literature developed up to now has mainly stressed the importance of volatility in the formation of prices rather than the impact of a trend (Baffes and Haniotis, 2010; Gilbert and Morgan, 2010).

The empirical results of this study are in line with the fact that the volatility effect has played a major role; however, they show how this volatility became incorporated in the trend for wheat leading to the price spike. However, in the case of rice, an 
Table 5 State vector analysis and regression effects in final state at time 2012(4)

\begin{tabular}{|c|c|c|}
\hline & Wheat & Rice \\
\hline Level $\left(\mu_{T}\right)$ & $5.59[0.000]$ & $5.49[0.000]$ \\
\hline Slope $\left(\beta_{T}\right)$ & $0.011[0.04]$ & - \\
\hline Seasonal $x^{2}$ test & $29.8[0.000]$ & $11.63[0.008]$ \\
\hline Cycle1 $\left(\Psi_{\mathrm{T}}\right)$ amplitude & 0.045 & 0.049 \\
\hline \multicolumn{3}{|l|}{ Seasonal effects $\gamma_{\mathrm{T}}$} \\
\hline \multicolumn{3}{|l|}{ Period: } \\
\hline 1 & $0.023[0.002]$ & $0.009[0.386]$ \\
\hline 2 & $-0.034[0.000]$ & $0.002[0.866]$ \\
\hline 3 & $-0.009[0.185]$ & $0.005[0.657]$ \\
\hline 4 & $0.021[0.003]$ & $-0.016[0.138]$ \\
\hline \multicolumn{3}{|c|}{ Regression effects in final state at time 2012(4) } \\
\hline \multicolumn{3}{|l|}{ Interventions $\left(\mathrm{d}_{\mathrm{j}}\right)$ : } \\
\hline \multicolumn{3}{|l|}{ Coefficients } \\
\hline Lb 1986 (2) & $-0.21[0.004]$ & \\
\hline Lb 1986 (3) & & $-0.16[0.017]$ \\
\hline Lb 1987 (3) & & $0.32[0.000]$ \\
\hline Lb 1988 (2) & $0.21[0.002]$ & \\
\hline Lb 1990 (2) & & $-0.21[0.002]$ \\
\hline Lb 1993 (4) & & $0.39[0.000]$ \\
\hline Otr 1993 (4) & $0.14[0.003]$ & \\
\hline Lb 1994 (2) & & $-0.26[0.000]$ \\
\hline Otr 1995 (1) & $-0.13[0.005]$ & \\
\hline Lb 1996 (3) & $-0.27[0.000]$ & \\
\hline Otr 1998 (3) & -0.12 [0.009] & \\
\hline Otr 2002(3) & $0.284[0.000]$ & \\
\hline Otr 2002(4) & $0.15[0.010]$ & \\
\hline Lb 2006 (2) & $0.18[0.008]$ & \\
\hline Lb 2007 (3) & $0.26[0.000]$ & \\
\hline Lb 2007 (4) & & $0.19[0.006]$ \\
\hline Lb 2008 (1) & $0.21[0.003]$ & \\
\hline Otr 2008 (1) & & $0.53[0.000]$ \\
\hline Lb 2008 (2) & & $0.76[0.000]$ \\
\hline Lb 2008 (4) & $-0.32[0.000]$ & $-0.23[0.002]$ \\
\hline Otr 2009 (1) & & $0.08[0.073]$ \\
\hline Lb 2009 (3) & $-0.36[0.000]$ & \\
\hline Lb 2010 (3) & $0.52[0.000]$ & \\
\hline Otr 2011(4) & $-0.11[0.022]$ & \\
\hline
\end{tabular}

Notes: $\mathrm{Lb}$ is for Level Break, Otr is for Outliers and $\mathrm{SI}$ is for Slope. Values in brackets are $\mathrm{p}$-values

exogenous shock led to the price spike. More specifically, after 2002, cycle 1 of wheat had increased price fluctuations, which reached their peak in 2008 when the price spike is recorded. However, cycle 2 had its highest fluctuation just before the initiation of the increasing volatility of cycle 1 . Since China reduced its stocks at that time, there would a justification in saying that the driver of cycle 2 represents the information for stocks. Furthermore, the empirical results state the importance of cycle 2 for the price 
Table 6 State vector anti-log analysis at period 2012(4)

\begin{tabular}{lll}
\hline & Wheat & Rice \\
\hline Level (anti-log) & $269.9[0.000]$ & $243.8[0.000]$ \\
Slope (yearly \% growth) & $4.5[0.042]$ & - \\
Seasonal $x^{2}$-test & $29.8[0.000]$ & $11.6[0.008]$ \\
Cycle 1 magnitude (\%trend) & 4.5 & 4.9 \\
Seasonal effects: & & \\
Period & Value Prob \%Effect & Value Prob \%Effect \\
1 & $1.022[0.002] 2.2$ & $1.010[0.386] 1.1$ \\
2 & $0.966[0.000]-3.3$ & $1.001[0.866] 0.2$ \\
3 & $0.991[0.185]-0.9$ & $1.005[0.657] 0.5$ \\
4 & $1.022[0.003] 2.2$ & $0.983[0.138]-1.6$ \\
\hline
\end{tabular}

Notes: Values in brackets are p-values

formation of wheat, something that is expected for stocks. On the other hand, the two price cycles of rice exhibited smooth behavior during the whole period under examination, whereas the irregular component presents structural breaks and outliers, especially during 2008. These statistical results for the rice market account for the fact that the narrow international rice market was severely affected by the decision of the Indian Government to place a limit on exports in an effort to counterbalance the effect of rising wheat prices on the cost of living. The response of the rice importing countries was such that prices increased dramatically. In mid-2008, the price increase was intercepted by the move of the Japanese Government to sell rice from its World Trade Organization stockpile.

The novelty of this study is that employing the structural time series analysis with the means of the cycles for wheat and an irregular component for rice gives size and shape to the factors that affect price formation. The instability of prices and their effect on the trend affect less developed countries to a greater extent than the more developed countries. The same applies to the poorer and richer consumers within a country. However, knowledge of the structure of the two price series will enhance the efforts of policy makers to counterbalance the negative effects of the cyclicality of wheat prices and the vulnerability of rice prices to exogenous factors. More specifically, when policy makers were faced with increased prices that threatened the food security of their countries they resorted to counter measures that only helped in the short term, such as export bans and subsidized prices. However, sooner rather than later, these measures

Table 7 Normality tests $\left(x^{2}\right)$ for auxiliary residuals

\begin{tabular}{llll}
\hline & Skewness & Kurtosis & Bowman-Shenton \\
\hline Wheat & & & \\
Irregular & $0.128[0.721]$ & $0.247[0.618]$ & $0.376[0.828]$ \\
Level & $1.426[0.232]$ & $0.0033[0.953]$ & $1.431[0.489]$ \\
Slope & $1.255[0.262]$ & $0.257[0.611]$ & $1.512[0.469]$ \\
Rice & & & \\
Irregular & $0.036[0.849]$ & $1.256[0.263]$ & $1.293[0.524]$ \\
Level & $0.551[0.459]$ & $0.038[0.841]$ & $0.588[0.745]$ \\
\hline
\end{tabular}

Notes: Values in brackets are p-values 

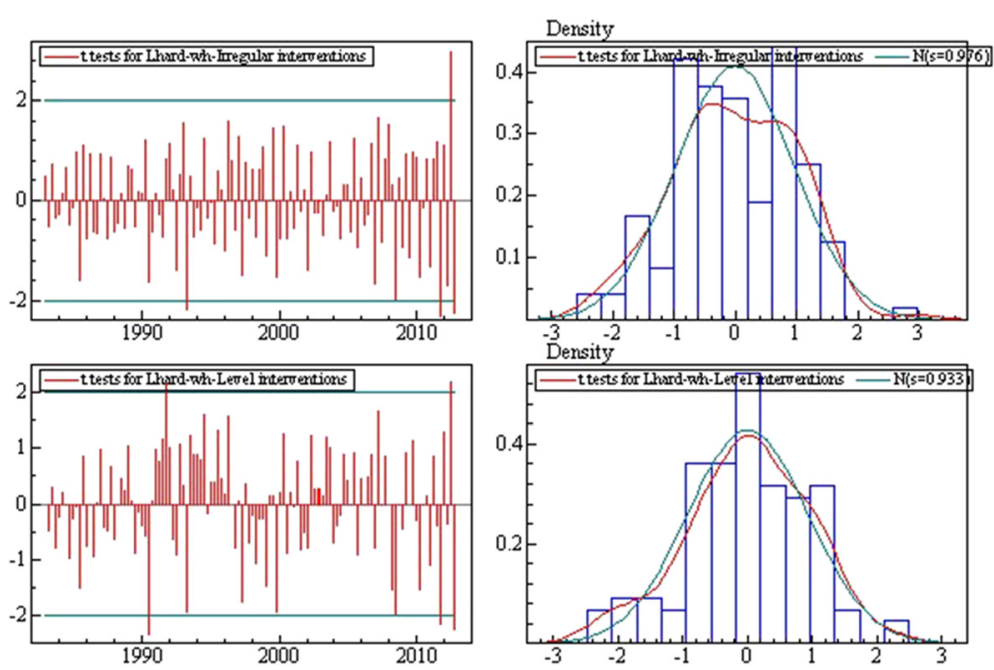

Fig. 7 Auxiliary residuals: irregular and level for Wheat price index (Lhard-Wh)

lost their effectiveness, and in the absence of long-term measures, social unrest increased while the costs created deficits. Since, this study shows that wheat prices are affected by short-run fluctuations that govern the price formulation in the long run, it is evident that short-run measures should be enhanced from longer term ones, as well. The main measure to be taken would be stock building. Before the correlated price spikes in agricultural commodities, trade was a good alternative measure; however, the experiences of 2008 have revealed that at times when the international markets are closed to poor countries due to high prices and reduced trading, increased stocks are valuable for securing the food supply for these countries (Gilbert and Morgan, 2010). Since stock-building is an expensive and inflexible measure, and thus difficult for poorer countries to adopt, the aim of governments should be joint stock-building with other net-importing countries. Moreover, the involvement of the private sector in stock building could ease the burden for governments. Furthermore, policy measures with
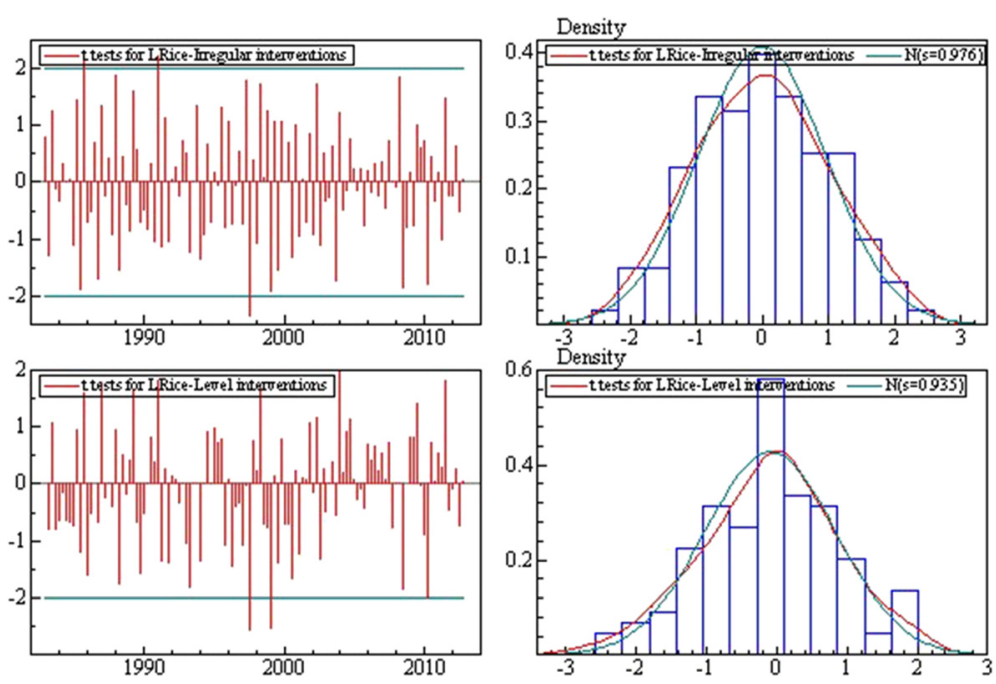

Fig. 8 Auxiliary residuals: irregular and level for Rice price index (LRice) 

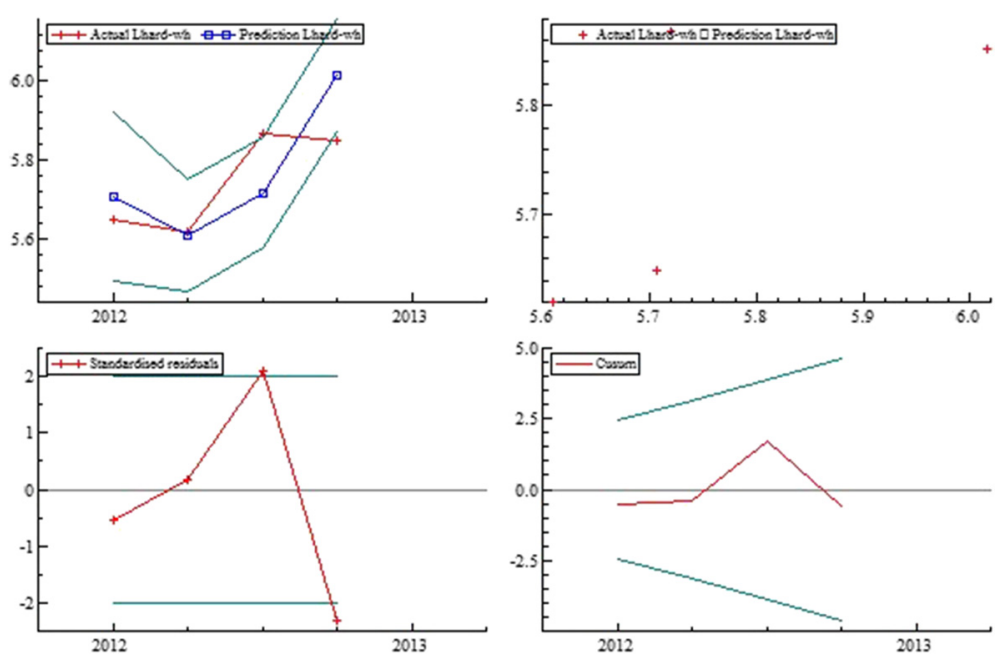

Fig. 9 Prediction testing for the Wheat price index (Lhard-Wh)

the same rationale should be developed by less developed countries so that they will be able to have access to the hedging markets of futures and options. On the other hand, richer countries are not so worried about their food security as much as the effects of food prices on inflation. Despite the fact that developed countries are both more open to world markets and more capable of isolating their farmers from world market volatility, they would also benefit from cooperating with the less developed countries on mitigating the undesirable effects of high food prices.

The above analysis indicates that policy makers should use the right mix of policies, depending on the staple food products of their country as well as their country's economic strength. In this way, structural time series analysis can be a valuable tool for policy makers.
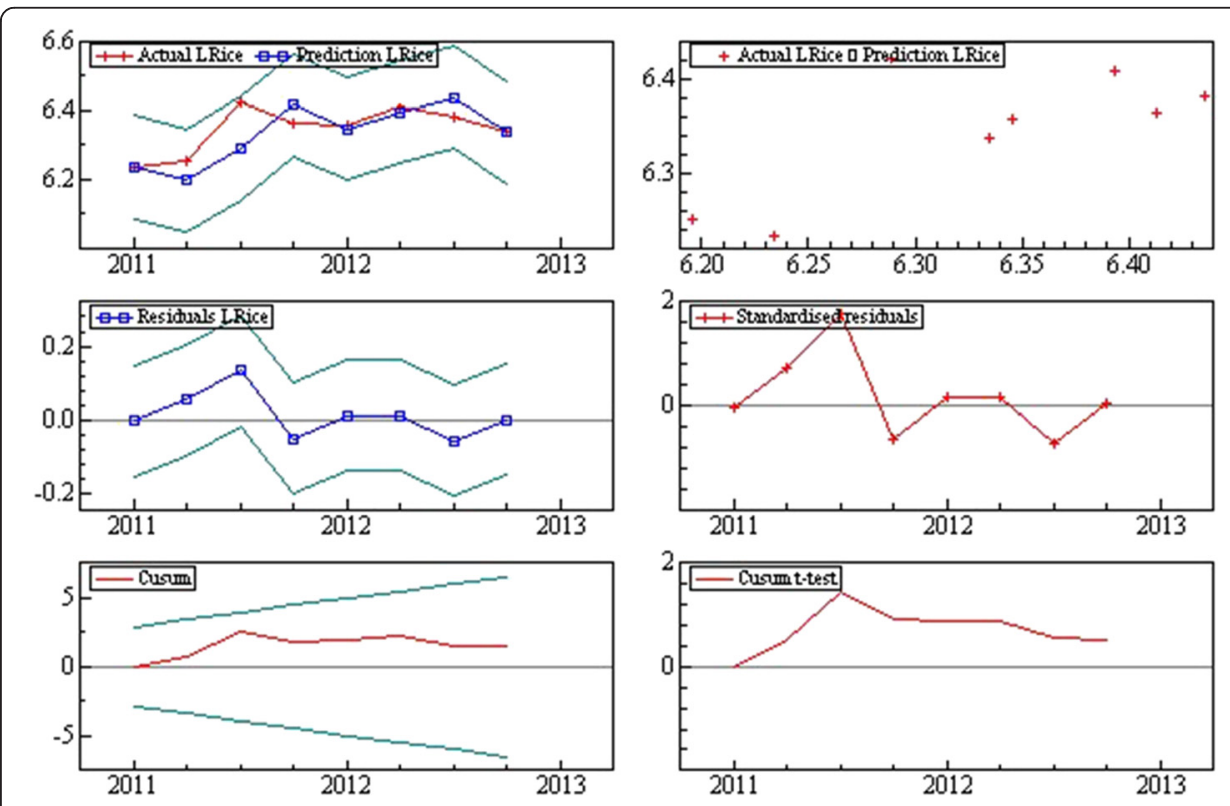

Fig. 10 Prediction testing for the Rice price index (LRice) 
Table 8 Post-sample prediction tests on hard wheat (Lhard-Wh) and rice (LRice) price index

\begin{tabular}{lr}
\hline Wheat & Predictive test \\
Failure $x_{8}^{2}$ test & $11.626[0.168]$ \\
Cusum $t(8)$ test & $-0.596[1.432]$ \\
Rice & \\
Failure $x_{8}^{2}$ test & $4.751[0.783]$ \\
Cusum $t(8)$ test & $0.526[0.613]$ \\
\hline
\end{tabular}

Notes: Values in brackets are p-values

\section{Conclusions}

The present study has analyzed the international prices of wheat and rice from 1983(1) to 2012(4) using the structural time series analysis. The price series were decomposed into their trend, seasonal, cyclical, and irregular components. The decomposition process provided knowledge on the stylized facts of the international wheat and rice quarterly prices.

The importance of this study is that it has given size and shape to the cyclicality and irregular component of the price series of wheat and rice, which are shown to be the drivers of the price formation mechanism. Moreover, the structural time series analysis is not based on achieving stationarity, something that could be difficult in the presence of an intense price spike such as that of 2008. Furthermore, identifying the interrelationship of the decrease of the Chinese grain stocks with the 2008 wheat price spike would not be possible without the information acquired by the structural analysis. The paper does not state that if the Chinese stocks had not decreased, the price surge would not have taken place, but it has identified that a major factor that held back the growth rate of prices ceased to exist. Finally, the outcome of this study emphasizes the importance of considering wheat and rice as separate commodities requiring country-specific and commodity-specific policy measures.

\section{Endnotes}

${ }^{1}$ Both monthly and quarterly prices were used for the estimation of the STS models. However, the models estimated with the use of monthly price data series did not pro399 vide well specified statistical results. Therefore, quarterly price data series were used 400 because they generated well specified empirical results.

${ }^{2}$ The Hard Red Winter wheat as well as the Thailand rice prices are used as benchmarks of international prices for wheat and rice since they have the larger weight in 403 world production of wheat and rice, respectively.

Competing Interests

The authors declare that they have no competing interests.

\section{Authors' Contributions}

AR was the contributor of the conception and the design of the paper while he made critical revisions in its final draft. Also, AR has given the final approval of the version to be published and agreed to be accountable for all aspects of the work related to its accuracy or integrity. Furthermore, AR has contributed to the estimation of the model and the interpretation and analysis of the empirical results. AN and DP acquired the data, estimated the models, analyzed and interpreted the results while they involved in the drafting of the paper.

\section{Acknowledgements}

This research was supported by a grant from a Regional program of Western Greece.

This research has been co-financed by the European Union (European Social Fund - ESF) and Greek national funds through the Operational Program "Education and Lifelong Learning" of the National Strategic Reference Framework (NSRF) - Research Funding Program: Heracleitus II. Investing in knowledge society through the European Social Fund. 
Received: 19 June 2014 Accepted: 8 May 2015

\section{Published online: 10 June 2015}

\section{References}

Abbott PC, Hurt C, Tyner WE (2011) What's driving food prices in 2011? Farm Foundation Issue Report (FFIR). Available at: http://www.farmfoundation.org/news/articlefiles/1742-FoodPrices web.pdf

Baffes J, Haniotis T (2010) Placing the 2006/08 commodity price boom into perspective. The World Bank: Policy research working paper 5371. Available at SSRN: http://ssrn.com/abstract=1646794

Baldwin K, Childs N, Dyck J, Hansen J (2012) Southeast Asia's Rice Surplus. USDA (United States Department of Agriculture) Outlook: A Report from the Economic Research Service. Available at: http://www.clientadvisoryservices.com/ Downloads/RCS-12-31-2012_Special_Report.pdf

Bhar R, Hamori S (2007) Component structures of agricultural commodity futures traded on the Tokyo Grain Exchange. Asia-Pacific Finan Markets 13:1-9

Bollerslev T (1986) Generalized autoregressive conditional heteroskedasticity. J Econ 31:307-327

Box GEP, Jenkins GM (1976) Time series analysis: forecasting and control. Revised edn. Holden-Day, San Francisco

Chidmi B, Fatiga ML (2007) Dynamics of Price-cost Margins in the US Meat Industry. Paper prepared for presentation at the American Agricultural Economics Association Annual Meeting Portland OR July 29-August 1. Available at: http://core.kmi.open.ac.uk/download/pdf/7025801.pdf

Christiaensen L (2009) Revisiting the global food architecture: lessons from the 2008 crisis. WIDER discussion paper 2009/04. UNU-WIDER, Helsinki

Crispin MK, Dale C (1998) Modeling US broiler supply response: a structural time series approach. Agri Resource Econ Rev 27(2):241-251

Deaton A, Laroque G (1992) On the behavior of commodity prices. Rev Econ Stud 59:1-23

Dethier JJ, Effenberger A (2011) Agriculture and development - a brief review of the literature. Policy Res Working Paper 5553:1-58

Durbin J, Koopman SJ (2012) Time series analysis by state space methods. 2nd eds. Oxford, UK: Oxford University Press

Engle RF (1982) Autoregressive conditional heteroscedasticity with estimates of the variance of United Kingdom inflation. Econometrica 1982(50):987-1006

Faliva M (1994) Trend-cycle detection as a filtering problem. J Italian Statistical Soc 3:315-338

FAO (2009) Wheat flour. Agribusiness handbook. Available at: https://www.responsibleagroinvestment.org/sites/ responsibleagroinvestment.org/files/FAO_Agbiz\%20handbook_Wheat\%20Flour.pdf

Farley EV Jr, Murphy JM (1997) Time series outlier analysis: evidence for management and environmental influences on sockeyes salmon catches in Alaska and northern British Columbia. Alaska Fishery Res Bull 4(1):36-53

Fatiga ML, Misra SK (2007) Common trends, common cycles and price relationships in the international fiber market. J Agric Resour Econ 32(1):154-168

Gilbert CL, Morgan CW (2010) Food price volatility. Philos Trans R Soc B 365:3023-3034

Gilbert CL (2006) Trends and volatility in agricultural commodity prices. In: Sarris A, Hallam D (eds) Agricultural commodity markets and trad. Edward Elgar, Cheltenham UK, pp 31-60

Harvey CA (1989) Forecasting, structural time series models and the Kalman filter. Cambridge, UK: Cambridge University Press Heymans A (2008) Managing an Agricultural Commodities Portfolio in South Africa with pairs trading. Thesis submitted to the centre for Business Mathematics and informations of the North-West University (Potchefstroom Campus) in fulfillment of the requirements for the degree of Philosophiae Doctor (Risk Management). Available at reserch gate: http://www.researchgate.net/publication/

38115421_Managing_an_agricultural_commodities_portfolio_in_South_Africa_with_pairs_trading_Andr_Heyman

Inter-agency Report (2011) Price Volatility in Food and Agricultural Markets: Policy Responses. Available at OECD: http:// www.oecd.org/tad/agricultural-trade/48152638.pdf

Kalman RE (1960) A new approach to linear filtering and prediction problems. J Basic Eng Transac ASME Series D 82:35-45

Koopman SJ, Harvey AC, Doornik JA, Shephard N (2009) STAMP 8.2: structural time series analyser, modeller and predictor. Timberlake Consultants, London

Mirzabaev A, Tsegai D (2012) Effects of weather shocks on agricultural commodity prices in Central Asia. Zentrum für Entwicklungsforschung (ZEF) Center for Development Research Discussion Papers on Development Policy No. 171. Available at SSRN: http://ssrn.com/abstract=2188353

OECD (2008) Rising Agricultural prices: causes, consequences and responses. Policy Brief

Rezitis AN, Sassi M (2013) Commodity Food Prices: Review and Empirics. Economics Research International 2013(694507):15 Hindawi Publishing Corporation. Available at: http://dx.doi.org/10.1155/2013/694507

Shepherd B (2006) Estimating Price Elasticities of Supply for Cotton: A Structural Time-Series Approach. Munich Personal RePEC Archive (MPRA) Paper No. 1252. Available at: http://mpra.ub.uni-muenchen.de/1252/

Sims C (1982) Macroeconomics and reality. Econometrica 48(1):1-48

Timmer CP (2010) Management of rice reserve stocks in Asia: analytical issues and country experience. Commodity Market Review 2009-10. FAO, Rome Italy, pp 87-120

Ubide A (1997) Determinants of Inflation in Mozambique. IMF (International Monetary Fund) Working Paper/97/145. Available at: http://www.imf.org/external/pubs/ft/wp/wp97145.pdf

Wright BD, Williams JC (1991) Storage and commodity markets. Cambridge University, Cambridge, UK 